\title{
CORRELATION BETWEEN TRUNK MUSCLE FUNCTION AND RISK OF FALLS IN ELDERLY WOMEN WITH OSTEOPOROSIS
}

Madeline Luiza Ferreira Pivovarsky1,*, Renata Gonçalves Pinheiro Corrêa ${ }^{1}$, Liliana Laura Rossetin ${ }^{1}$, Daniela Gallon Correa ${ }^{1}$, Heloísa Salamoni de Araújo ${ }^{1}$, Gabriela de Almeida Tormes ${ }^{1}$, Neiry Ellen Gasperin Arsie ${ }^{1}$, Amanda Colombo Peteck Lopes ${ }^{1}$, Victoria Zeghbi Cochenski Borba ${ }^{2}$, Ana Carolina Brandt de Macedo ${ }^{1}$, Anna Raquel Silveira Gomes ${ }^{1}$

1.Universidade Federal do Paraná, Curitiba (PR), Brazil. 2.Universidade do Paraná, Curitiba (PR), Brazil.

*Corresponding author: madeline8497@gmail.com

\section{BACKGROUND}

Fall is the main risk factor for fracture in women with osteoporosis, which present high levels of physical inactivity, compression fractures, pain, postural alterations and musculoskeletal disfunctions in the trunk, which can impair balance and lead to falls. The objective of this study was to verify the correlation between trunk muscle function, functional mobility, balance and fall risk in women with osteoporosis.

\section{MATERIALS AND METHODS}

This research included women with osteoporosis over the age of 65. Trunk range of motion (ROM) was evaluated with a goniometer; lordosis angle with flexicurve; trunk flexors and extensors isometric peak of force (IPF) was assessed by a hand-held dynamometer. The functional mobility and balance (FMB) were evaluated by the Timed up and Go Test; risk factor for falls (RFF) with the Physiological Profile Approach. Normality was tested with Shapiro-Wilk; Pearson or Spearman was used for correlation between variables and linear regression to establish a relationship between dependent and independent variables.

\section{RESULTS}

Nineteen women (72.36 \pm 6.19 years) enrolled the study, with a body mass index of $30.04 \pm 6.50 \mathrm{~kg} / \mathrm{m}^{2}$ - overweight. The FMB can be explained in $31.1 \%$ by left trunk rotation ROM ( $r=-0.598 ; p=0.014)$; in 38.8\% by lumbar lordosis $(r=-0.660 ; p=0.010)$; and in $34.1 \%$ by trunk muscle flexors IPF $(r=-0.623 ; p=0.013)$. The RFF can be explained in $16.1 \%$ by trunk extension ROM $(r=-0.577 ; p=0.019)$.

\section{CONCLUSION}

It might be recommended exercises to enhance trunk ROM and strength and postural exercises in the interventions to treat risk of falls in older women with osteoporosis.

\section{ACKNOWLEDEGMENTS}

Universidade Federal do Paraná. Complexo Hospital de Clínicas UFPR. Programa de Pós-Graduação em Educação Física da UFPR. Programa de Pós-Graduação em Medicina Interna da UFPR. Serviço de Endocrinologia e Metabologia do HC-UFPR. Coordenação de Aperfeiçoamento de Pessoal de Nivel Superior- Brasil (CAPES). Conselho Nacional de Desenvolvimento Científico e Tecnológico - CNPq. Sanepar. DSYS LAB. 